\title{
A contribuição do pensamento de Paul Tillich para a importância da religião nas culturas urbanas da atualidade
}

\author{
Carlos Alberto Motta Cunha ${ }^{1}$
}

\section{RESUMO}

O pensamento de Paul Tillich continua atual e desafiador. Em 2019, completa 100 anos da conferência proferida por ele na sociedade kantiana de Berlim, 16 de abril de 1919, intitulada "Sobre a ideia de uma teologia da cultura". A explanação de Tillich é tida como o marco inicial da sua Teologia da Cultura e fonte de inspiração para pensar a correlação entre religião e cultura. Em comemoração a esse referencial, a reflexão aqui proposta busca fazer alguns apontamentos introdutórios sobre a contribuição do pensamento tillichiano para a importância da religião nas culturas urbanas da atualidade. Para isto, o texto está dividido em dois momentos. Primeiro, uma breve análise da crise da religião, do sujeito religioso e da devoção ao mercado financeiro, segundo, a teologia da cultura de Tillich empenhada em ressignificar os símbolos da fé e correlacionar religião e cultura como caminho de busca de sentido para o ser humano de hoje. Palavras-chave: Religião. Cultura. Teologia. Urbanização. Paul Tillich

\section{Paul Tillich's Contribution Concerning \\ The Importance of Religion in Nowadays Urban Cultures}

\section{ABSTRACT}

Paul Tillich's thought remains timely and challenging. On April 16th 2019 , it was the $100^{\text {th }}$ anniversary of his lecture delivered to Berlin Kant society. It was entitled "On the idea of a theology of culture". Tillich's presentation is considered the starting point of his Theology of Culture and the source of inspiration for his thinking on the correlation between

\footnotetext{
Doutor em Teologia com pós-doutorado em Teologia Sistemática pela Faculdade Jesuíta de Filosofia e Teologia, professor adjunto no Instituto de Filosofia e Teologia Dom João Resende Costa (IFTDJ) da PUC Minas, pesquisador de grupos de pesquisa da CAPES e do CNPq. E.mail: carlosamc04@gmail.com.
} 
religion and culture. In order to commemorate this landmark, the paper presents some introductory notes on Tillich's contribution concerning the importance of religion in nowadays urban cultures. To do so, the text is divided into two parts. First, a brief analysis of the religion crisis, the religious subject, and of the cult of the stock market. Second, Tillich's theology of culture, committed to resignifying the symbols of faith and to correlating religion and culture as the way human beings' search for meaning in today's world.

Keywords: Religion. Culture. Theology. Urbanization. Paul Tillich.

\section{Introdução}

A palavra "crise", de origem grega krisis, significa julgar, discernir. Ao localizar a utilização do termo pelas culturas atuais, percebemos que a tensão é proveniente da desorientação das sociedades que questionam os modelos adquiridos, a impressão de que já não existem parâmetros ou referências institucionais. A crise não é pela falta de conhecimento e, sim, de orientação; não somos ignorantes, estamos confusos, faltam-nos critérios de discernimento.

A crise afeta todas as dimensões da vida e inclusive a dimensão da religião. "De fato, a crise da religião é um dado fundamental de nosso tempo", afirma o antropólogo francês René Girard (GIRARD, 2012, p.11). A lógica dos centros urbanos pede uma configuração religiosa própria. Caso não seja feita uma contextualização da religião e adequação e releitura dos seus símbolos, a religião perde o seu valor e significado. O conceito de desafeição religiosa (RIBEIRO, 2012) ajuda a compreender o desencantamento religioso de algumas pessoas.

É neste contexto de crise religiosa que a contribuição de Paul Tillich emerge. A riqueza das suas reflexões filosófico-teológicas revela um tema transversal: a dimensão religiosa de toda cultura. "O problema da relação entre religião e cultura sempre esteve no centro de meus interesses. A maioria de meus escritos tenta definir a maneira como o cristianismo se relaciona com a cultura secular", afirma Tillich (TILLICH, 2009, p.33). Assim, o nosso texto busca apontamentos introdutórios sobre a contribuição do pensamento tillichiano para a importância da religião nas culturas urbanas da atualidade. O caminho para isto é: Primeiro, uma breve análise da crise da religião, do sujeito religioso e a 
devoção ao mercado financeiro, segundo, a teologia da cultura de Tillich empenhada em ressignificar os símbolos da fé e correlacionar religião e cultura como caminho de busca de sentido para o ser humano de hoje.

\section{A crise da religião e do sujeito religioso}

A crise civilizatória de hoje toca inevitavelmente a dimensão da religião. O âmbito da crença faz parte de uma cultura. Juntamente com a visão de mundo, valores e comportamento, o aspecto religioso, com toda a sua diversidade, compõe o universo de significado de um povo (cf. LAPLANTINE, 2003, p.149-165). Enquanto realização social e individual, a crença em uma realidade suprema, seja ela compreendida da maneira que for, manifesta os seus efeitos sobre uma tradição e sobre uma comunidade. A religião, religiosidade e fé compõem um emaranhado de sentidos. Segundo João Batista Libanio, a religião dá sentido a uma dimensão profunda das pessoas. Enquanto tal, ela se organiza num sistema de ritos, doutrinas e práticas. A fé, elemento constitutivo da religião, remonta a uma Palavra revelada acolhida pelo fiel. Já a religiosidade busca responder à dimensão subjetiva de abertura da pessoa ao Mistério (LIBANIO, 2002a, p.55).

Essa tríade proposta por Libanio no âmbito da crença - religião, religiosidade e fé -, sugere que ao se falar em crise da religião também está se falando da crise do sujeito religioso, isto é, na atualidade, no mundo cada vez mais urbano, deparamo-nos não só com o conflito no sistema de ritos, doutrinas e práticas, mas, sobretudo, com a desordem pela falta de sentido do ser humano contemporâneo. Esta "fragmentação do ethos - nossa matriz de percepção, de avaliação e de ação não nos dá mais a base consensual de sustentação comum" (cf. AGOSTINI, 2002, p.9-46), provocando o afastamento do humano de si mesmo, do seu próximo, da natureza e do Divino. O ser humano de hoje não se sente em casa. O mundo ao seu redor lhe parece estranho.

Temos a impressão de que a crise na dimensão da crença varia entre os hemisférios. No sul global presenciamos uma revitalização das religiões. Em alguns casos, principalmente no islamismo, a renovação das religiões tradicionais está estreitamente vinculada a um nacionalismo emergente, a projetos de construção nacional e processos afins. Enquanto que o número de cristãos triplicou desde o início do século 
passado, o de muçulmanos quadruplicou. O hinduísmo não é assertivo apenas no Oriente, mas suas doutrinas e práticas estão fazendo adeptos com êxito em algumas partes do Ocidente também. O mesmo se pode dizer do budismo. Na América Latina, o pentecostalismo evangélico e a renovação católica carismática têm dado novos ares de renovação ao cristianismo. No Brasil, por exemplo, o censo religioso do Instituto Brasileiro de Geografia e Estatística (IBGE) mostra que durante o período intercensitário, entre os censos de 2000 e 2010, os evangélicos eram $15,4 \%$ da população. Hoje, são 22,2\%. O aumento foi de 16 milhões de fieis. De 26,2 milhões em 2000 para 42,3 milhões em 2010. Destes 42,3 milhões de evangélicos, $60 \%$ são de origem pentecostal. $\mathrm{O}$ pentecostalismo é o grupo religioso que mais cresce no país.

Já no hemisfério Norte a situação é outra. Não é novidade afirmar que países que estão acima da linha do Equador vivem um período irreligioso. O ser irreligioso, e não a-religioso, diante do descrédito das ideologias e utopias, busca experiências de bem-estar espiritual e corporal numa espécie de reencantamento do mundo, do ser humano e dos deuses. Balizado pelo "crer sem pertencer", sociedades dos países considerados "desenvolvidos" têm uma relação peculiar com a religião a partir de uma nova configuração. As religiões são vistas como movimentos pré-modernos e o seu legado consiste em promover a moralidade, engendrar um espírito de comunidade e inspirar a arte e a arquitetura. "Num mundo ameaçado por fundamentalistas religiosos ou seculares, deve ser possível equilibrar uma rejeição da fé e uma reverência seletiva por rituais e conceitos religiosos", afirma Alain de Botton (BOTTON, 2011, p.12). Longe da pertença religiosa e adesão doutrinária, o sujeito secularizado dos grandes centros urbanos de hoje vê nas religiões um escape universal para duas questões perturbadoras que afligem a humanidade: como viver em comunidade e como lidar com a dor. "Deus pode estar morto, mas as questões urgentes que nos impulsionaram a inventá-lo ainda nos sensibilizam", conclui Botton (Ibidem).

\subsection{Devoção ao mercado financeiro}

A crise religiosa é complexa. O mal-estar provocado pela indefinição do tempo presente possibilita diagnósticos díspares sobre o futuro ou não da religião. Enquanto uns acreditam numa crise que 
afeta a religiosidade em suas raízes mais profundas, levando-a ao seu desaparecimento e fazendo com que o ser humano caia no ateísmo e no niilismo, outros apostam num momento de retorno ao Sagrado, de indubitável efervescência religiosa numa reconstrução das estruturas religiosas. Os estudiosos da religião sugerem que a crise de hoje apresenta as seguintes características: primeira, a crise não é terminal para o religioso, e sim de mudança estrutural; segunda, as religiões históricas tradicionais perderam a sua força por não conseguirem ter o que dizer à atual geração; e, terceira, observa-se uma emergência de novas formas religiosas criativas potencializando a espiritualidade humana (cf. CORBÍ, 2010). Uma espiritualidade leiga, uma "religião" sem deuses, um Jesus sem o Cristo e um Reino sem Deus parecem ser a tendência do humanismo ateu e agnóstico do tempo presente.

A cidade, com todo processo de urbanização, não só afastou o ser humano da natureza como transformou a relação dele com Deus, os deuses, a Transcendência ou o nome que se dê a uma Realidade maior. O policentrismo urbano tem uma lógica de configuração dos espaços que rejeita os centralismos religiosos (LIBANIO, 2002b, p.56). Ele é diferente do mundo rural onde a religião é centralizada, fazendo com que a sociedade teocêntrica assuma valores, crenças e comportamentos de um sistema religioso dominante. Nas grandes cidades há pluralismo religioso e oportunidades para diálogos interfé, inter-religioso e ecumênico. ${ }^{2}$ A promoção de tal postura de respeito e tolerância vai depender do centro predominante.

Libanio faz uma análise sobre o impacto dos centros dominantes - tecnociência, virtual, religioso espacial, clerical - sobre a religião, religiosidade e fé. Dentre os centros citados, há o neoliberal, que alinha perfeitamente com a nossa reflexão. Por mais que a cidade seja um lugar plural e favoreça intercâmbios de modos de vida, existe o pensamento que resiste à alteridade e almeja se impor de forma única. O neoliberalismo é assim. A sua uniformidade proposta é regida por um nexo econômico e político anti-humano, porque aliena o indivíduo da

\footnotetext{
2 Aqui há uma distinção importante. O diálogo interfé é uma referência ao encontro entre fiéis "leigos" de tradições religiosas diferentes. O diálogo inter-religioso consiste na partilha comum entre as religiões muito presente no âmbito acadêmico. Já o ecumenismo sugere o diálogo entre grupos de uma mesma tradição de fé.
} 
sua humanidade plena; irracional, porque mensura a realidade humana pela capacidade de posse; injusto, porque segrega criando bolsões de despossuídos de condições mínimas para a sobrevivência (LIBANIO, 2002 b, p.60). O mercado se impõe como uma divindade perversa fomentando individualismo, consumo desenfreado e indiferença nos seus seguidores. $\mathrm{O}$ centro neoliberal perverte e instrumentaliza o âmbito da crença ao ponto de gerar barganhas entre o indivíduo e a divindade e a venda de "produtos religiosos". O espaço da fé se converte em casa de negócio e o religioso se transforma em empreendedor das coisas "sagradas".

A grande tentação do centro neoliberal para as religiões é fazer com que as tradições de fé percam a sua natureza profética, isto é, abandonem a sua natureza crítica, militante e libertadora dos desmandos da injustiça social, econômica, política e outras. Acomodam-se ao sistema em um processo de privatização e de secularização. Nesta relação de interesses, as religiões deixam de lado a sua função de religare entre o humano e a criação para assumirem uma aproximação para a alienação. Segundo Libanio:

O individualismo neoliberal fomenta concorrência e competição em que vencem os mais fortes, os mais preparados e competentes. Visa o resultado. É necessário encontrar uma religião que reforce a vitória, a prosperidade dos melhores. Recorre-se, então, à teologia da bênção de Deus para os ricos e ao castigo para os pobres, porque preguiçosos e pecadores. É uma teologia feita sob medida para alimentar igrejas que sustentam o sistema neoliberal. Evidentemente, nessa religião não cabem práticas de solidariedade, de opção pelos pobres. É uma religião tipicamente materialista (LIBANIO, 2002a, p.155-156).

Movimentos religiosos pautados pelo sistema neoliberal de mercado, não estão preocupados com os direitos Humanos e da Natureza. A lógica que rege o seu fazer "teológico" é desumana e extrativista. A ideologia do progresso e da prosperidade cria relações de barganha com o outro visando o bem-estar pessoal. Neste jogo de interesses é o indivíduo que interessa e não a coletividade. O individualismo dita as regras de convívio social. As relações de coisificação criadas por esse ambiente são canalizadas em processos egocêntricos visando à prosperidade financeira como fim em si mesmo. As mobilizações sociais que 
emergem daí conseguem, no máximo, atitudes de assistencialismo ou paternalismo (CUNHA, 2017, p.156).

\section{A teologia da cultura de Paul Tillich}

As comunidades de fé não são entidades abstratas, mas constituídas por pessoas historicamente situadas na concretude da realidade humana. As religiões são contracultura quando se posicionam diante das injustiças com a missão de lutar a favor daqueles que foram marginalizados. O centro neoliberal criou o espaço da periferia; o lugar do subalternizado e excluído. É também o lugar da crítica de quem refuta a centralidade neoliberal dos poderosos retentores do capital. Espaços religiosos que assumem o compromisso como os oprimidos testemunham publicamente o espírito profético de uma religião genuína. "Só eles (os oprimidos) podem denunciar a 'ordem' que os esmaga e, na práxis da transformação desta 'ordem', anunciar um mundo novo a ser refeito constantemente", afirma Paulo Freire (FREIRE, 1981, p.88). Ser uma só voz com os oprimidos deveria ser a meta das religiões. Assim, elas têm o que dizer ao mundo urbano e globalizado. Trata-se de comprometer-se com as "vítimas da história", dizia Jon Sobrino (cf. SOBRINO, 2000).

A contextualização das religiões se dá quando existem adequação e releitura dos seus símbolos. Caso contrário, elas perdem o seu valor e vão deixando de ser significativas. Para Paul Tillich só se pode falar do Transcendente numa linguagem simbólica, que preserve o caráter sagrado, "totalmente outro", do que se busca. Essa linguagem desafia as definições precisas típicas dos meios acadêmicos, mas dela não se pode escapar, pois qualquer nova tentativa de definição arrastará as palavras para o campo subjetivo. As verdades eternas das religiões devem ser apresentadas por meio de símbolos e não por sistemas doutrinários rígidos, pois só a expressão simbólica possui uma base adequada para apontar para além de si mesma. A opção pela poiesis e não pela theoria se justifica diante do fato de se tratar de um Mistério. Neste sentido, os símbolos religiosos desvelam a dimensão profunda do real, e remetem a uma dimensão que transcende toda realidade condicionada, tornando possível a experiência da dimensão da profundidade, a experiência do Incondicionado. 
Segundo Tillich:

O nome desta infinita e inexaurível profundidade e base de todo o ser é Deus. Essa profundidade é o que significa a palavra Deus. E se essa palavra não tem grande sentido para ti, tradu-la, e fala das profundidades da tua vida, da fonte do teu ser, da tua máxima preocupação, daquilo que tomas a sério sem qualquer reserva. Talvez, para conseguir isso, devas esquecer tudo quanto de tradicional aprendeste acerca de Deus, talvez mesmo a própria palavra. Sabes já muito de Deus se souberes que Deus significa profundidade [...] Quem conhece a profundidade conhece a Deus [...] Este fundo infinito e inexaurível da história tem o nome de Deus. É isto que a palavra significa, e a isto se referem as expressões Reino de Deus e Providência de Deus (TILLICH, 1948, p.63).

A linguagem religiosa é aproximativa e inconclusa. Jamais se espera abarcar o Mistério na sua totalidade por meio de conceitos teóricos. Enquanto linguagem simbólica, o discurso da fé é polissêmico e contextual. A proposta da ressignificação tillichiana abre possibilidades de novas releituras de temas religiosos despidos das amarras ocidentais totalitárias. Ao optar por "profundidade" e não por "altura", quer dizer, um "Deus lá de cima" pelo "Deus próximo e profundo", Tillich traz a concepção do divino para perto do horizonte de significados do ser humano. "Tudo o que a religião afirma sobre Deus, inclusive suas qualidades, ações e manifestações, tem um caráter simbólico" (TILLICH, 2005, p.305). Portanto, o "Deus acima de Deus" (God above God) de Tillich é uma superação do imobilismo religioso desconectado dos tempos atuais (Cf. TILLICH, 1972).

Religiões pertinentes e críticas para o mundo urbano de hoje são aquelas que compreendem melhor a sua responsabilidade histórica a serviço do ser humano e da natureza. Sem querer ter monopólio da verdade sobre o Divino e das relações com Ele, as religiões conscientes de suas limitações não excluem outras experiências de fé e se posicionam na atualidade como religiões de alteridade. As suas teologias, enquanto discursos interpretativos, não são somente expressões diferentes de conteúdos de fé sempre idênticos, que escapariam à historicidade. Elas são também interpretações atuais da própria fé. A teologia hermenêutica aplicável às religiões é, ao mesmo tempo, pensamento crítico e ação eficaz. Daí o discurso religioso seria menos proselitista e dogmático, e 
mais humano, criativo, ecológico e pacífico. O crer, o fazer e o experimentar devem se reinventar, a cada dia, já que são atividades humanas.

É um grande desafio para as religiões e suas teologias se refazerem diante do avanço da urbanização. "De acordo com o ONU-Habitat, desde 2007, mais da metade da população mundial vive em cidades e centros urbanos, e a estimativa é de que em 2050, com uma população projetada em 9 bilhões de pessoas, esse número chegará a 70\%" (Cf. ONU, 2016). Será que as religiões e suas teologias serão capazes de resistir à secularização das cidades?

\subsection{Ressignificar os símbolos da fé}

Realçar a substância do símbolo religioso numa nova nomenclatura para o sujeito urbano é de suma importância para uma religião e sua teologia que busca relevância na atualidade. Tillich, nesse sentido, dá uma enorme contribuição. Por exemplo, as categorias cristãs - Deus, pecado original, salvação, Jesus Cristo e Igreja -, sofrem, na atualidade, de suspeita ideológica a que foram submetidos no decorrer da história do cristianismo. Com o positivismo de Augusto Comte, que relegara a religião e a teologia ao mundo da infância da humanidade e das pessoas, os símbolos da fé entraram em crise de sentido por não comunicarem sentido ao sujeito na idade adulta da razão (LIBANIO; MURAD, 2001, p.84).

Redizer tais categorias como propõe Tillich - Incondicionado, Alienação, Cura, Novo Ser e Nova Realidade -, parece ser imperativo para a tarefa pública da teologia. Novas nomeações dos símbolos da fé podem favorecer um leque de possibilidades para uma apropriação daquilo que é fundamental na religião: a dimensão da profundidade na totalidade do espírito humano. Segundo Tillich:

A religião revela a profundidade da vida espiritual, encoberta, em geral, pela poeira de nossa vida cotidiana e pelo barulho de nosso trabalho secular. Dá-nos a experiência do sagrado, intangível, tremendamente inspirador, significado total e fonte de coragem suprema. Eis aí a glória do que chamamos de religião. Mas, além dessa glória, também aparece sua vergonha, quando ela se transforma em absoluto e despreza o mundo secular; quando faz de seus mitos e doutrinas, de suas leis e ritos, dimensões indiscutíveis e persegue os que não se submetem a isso (TILLICH, 2009, p.45). 
A presença da teologia na esfera pública persiste como relevante e necessária. Ela supõe um estatuto de saber que prepare o teólogo para ser uma voz capaz de levar, na sociedade plural, a contribuição construtiva das religiões para o bem da convivência humana e ambiental. Portanto, a ação do teólogo não pode somente se limitar a reproduzir o discurso da fé no interior das confessionalidades. Ele necessita ocupar o espaço público assumindo a correlação entre a Igreja e a cultura de forma inclusiva como projeto do Reino de Deus.

A mútua relação que a teologia da cultura de Tillich evoca é mais do que simples discursos e realidades paralelos. Estamos falando de relações no mundo humano como constitutivo da esfera do divino, quer dizer, a esfera do divino está em mútua relação com a realidade histórica. O projeto tillichiano aponta para o problema central do conhecimento religioso na correlação de sentido entre símbolos religiosos e aquilo que é simbolizado por eles. Aponta também para a correlação do sentido lógico entre conceitos que denotam o humano e aqueles que denotam o divino determinando as afirmações sobre Deus e o mundo. E, por fim e não menos importante, aponta ainda para a correlação do sentido fatual entre a preocupação última do ser humano e aquilo pelo qual ele se preocupa de forma última, qualificando a relação divino-humana dentro da experiência religiosa.

O método da correlação dá condições ao teólogo de se posicionar no espaço público e de participar ativamente de assuntos relacionados à vida humana e à criação. Tillich chama de "círculo teológico" esse espaço imaginário em que o teólogo, ciente da sua pertença, transita numa postura atenta à situação existencial e ao modo como transmitir a mensagem cristã. Este espaço favorece a possibilidade da teologia assumir formas diferentes na tentativa de dialogar com a cultura (TILLI$\mathrm{CH}, 2005$, p.26-29).

O diálogo com a cultura na teologia de Paul Tillich é importante nesse sentido, pois ele pergunta sobre o lugar da dimensão religiosa na vida humana, se ela teria um lugar próprio, se ela poderia substituir ou ser substituída por algum âmbito da vida ou mesmo se ela ainda teria lugar na forma como a vida se configura em nossos tempos. A conclusão que ele chega é a de que a dimensão religiosa se encontra em todas as dimensões da vida humana, conferindo-lhes profundidade. Para Tillich, 
a religião é algo constitutivo da natureza humana e a teologia ocupa um lugar de importância uma vez que lida com as questões últimas das culturas simbolizadas na palavra "Deus". Portanto, a correlação tillichiana dá pistas importantes para uma teologia que busca ser incultura e contextualizada.

Já que o ser humano é religioso, não por causa de uma instituição, mas por buscar o "sentido último" naquilo que faz e cria, trazer a público a discussão teológica constitui um retorno importante no processo de humanização. A modernidade, com todo o seu avanço tecnocientífico em busca de ordem e progresso a qualquer preço, não conseguiu por fim aos anseios questionadores sobre o "sentido último" na vida do sujeito "esclarecido". Pelo contrário, o desenvolvimento científico especializado foi capaz também de acentuar o vazio religioso no ser humano devido a um mundo que perdeu a dimensão da sacralidade.

Com uma nova configuração, o estatuto do indivíduo parece assinalar para as "questões últimas" a partir de um amálgama entre religião e ciência, espiritualidade e tecnologia, em que as instâncias se fundem em prol de um ser humano capaz de conjugar produção coletiva e satisfação pessoal ou competência no mercado de trabalho e felicidade nas realizações pessoais. Porém, o elemento religioso e o elemento científico parecem ser meros instrumentos para aquele que se acredita protagonista: o ser humano. Neste contexto, com a alta tecnologia ocupando espaços cada vez maiores na vida das pessoas, mesmo sem a consciência plena de seu impacto por parte dos usuários e na presença dos mais variados grupos e discursos religiosos, intui-se um "momento de fronteira", no qual a teologia readquire seu status de discurso público.

A teologia como discurso público não tem nada a ver com a pregação às massas. Estes são discursos a-religiosos, de caráter proselitista. O "público", neste tipo de discurso, é cativo por empatias criadas no processo de comunicação entre o pregador, emissor, e o povo, receptor, mediadas por uma mensagem incentivadora da instrumentalização do sagrado e pelo comércio de produtos religiosos. A lógica é a de mercado. A perversidade dessa linguagem consiste em se aproximar das pessoas para a alienação. Ela não conscientiza o ser humano para a libertação (Cf. LIBANIO; CUNHA, 2011, p.89-92). O discurso apologético destes grupos tem aparência de público, mas são prédicas voltadas para atender 
os interessados de uma multidão ávida por "comprar" as bênçãos de Deus. Tal exposição não atende às expectativas públicas em prol da verdade, justiça e cidadania. Grande parte destes discursos promovidos são pregações com um conteúdo doutrinário extremista, cujo objetivo é converter as pessoas para um estilo de "vida religiosa" que remonta ao papel da religião no mundo pré-moderno. Há certo anacronismo entre a sociedade da alta tecnologia e, ao mesmo tempo, uma prática religiosa medieval de compra e venda de produtos religiosos. De certa forma, querem apresentar caminhos para a salvação e fazer uma crítica velada ao contexto de diversidade e pluralidade no qual nos encontramos.

A teologia pública precisa se diferenciar desses grupos. Primeiro, ela precisa se assumir como teologia que trata de assuntos relacionados à fé, relacionados às "questões últimas", intuindo sentidos de profundidade para a vida; segundo, ela precisa ser pública, abrindo-se ao diálogo com a contemporaneidade nos espaços de escuta desta realidade em seus clamores mais profundos e esperanças mais significativas. Será teologia quando, de forma criativa, se tornar interlocutora na caminhada sem preocupações proselitistas. Será pública quando, nesta caminhada, desprendida de idealizações ingênuas e moralismos inúteis, oferecer-se em contribuição para a vida de todos.

\subsection{Correlação entre religião e cultura}

A correlação da teologia de fronteira tillichiana evidencia-se, sobretudo, na relação que ela institui entre religião e cultura secular. É dentro dessa perspectiva que Jorge Pinheiro faz a apresentação da edição brasileira do livro Teologia da Cultura de Paul Tillich. Afirma ele:

[...] três conceituações fundantes do pensamento de Tillich: (1) a correlação da mensagem com a situação existencial, (2) o aspecto simbólico da linguagem religiosa que evita a apropriação, o dogmatismo e a idolatria, (3) e o princípio protestante, que define a justiça como incondicionalidade, que não se encontra restrita ao campo denominacional, mas expressa uma busca humana (TILLICH, 2009, p.23).

Na correlação tillichiana, a ponte hermenêutica entre a fé, a Revelação cristã e a cultura moderna compõe a teologia apologética. Para a reflexão teológica pública, a relação de dependência entre a fé, a 
Revelação e a cultura forma a situação em que o teólogo está inserido e à qual ele deve estar atento. Situação, para Tillich, significa as "formas científicas, artísticas, econômicas, políticas e éticas nas quais os indivíduos e grupos exprimem as suas interpretações da existência", esclarece Pinheiro (Idem, p.24)

Sem a situação, não há perguntas. Sem perguntas a Answering Theology não tem sentido. Por isso, Tillich assume as bases da Reforma Protestante da Sola Scriptura, Sola Gratia e Sola Fides como princípios ("princípio protestante"), e não como formulações fechadas, que permitem o diálogo entre a Revelação e a existência humana. Para que a teologia tenha uma resposta, isto é, tenha o que dizer, ela não só precisa estar enraizada nas suas origens, mas discernir e interpretar o tempo presente a fim de inculturar-se de modo digno e relevante nas questões públicas. A Igreja que emerge desse contexto é, na teologia apologética tillichiana, uma instância da sociedade civil aberta a novos diálogos, com uma postura profética e uma disposição a reformas constantes. “A Igreja, no seu papel profético, é a guardiã que revela as estruturas dinâmicas da sociedade e se opõe a seu poder demoníaco, revelando-o, mesmo quando dentro dela", diz Tillich (Idem, p.92).

Em sua teologia da cultura, Tillich demonstra a preocupação com o entendimento da linguagem religiosa pelo seu destinatário. Ele sustenta que uma verdade bíblica eterna deve ser apresentada por meio de símbolos e não por sistemas teológicos rígidos, pois a linguagem religiosa é simbólica, e se esvaziarmos esse simbolismo, ela se tornará vazia e sem sentido. O símbolo participa da realidade com a capacidade de apontar para além de si mesmo. "O confronto da análise existencial com o símbolo, por meio do qual o cristianismo expressa a preocupação suprema, é o método adequado, tanto para a mensagem de Jesus, o Cristo, como para a situação humana redescoberta na cultura contemporânea", afirma Tillich (Idem, p.90).

Assim, a mensagem eterna do cristianismo poderá atravessar os séculos sem perder a sua força, adequando-se de forma satisfatória a cada nova situação. Para a teologia cristã, Cristo é o símbolo de Deus de modo que não há conhecimento de Deus fora de Jesus Cristo. A interpretação existencial do evento Cristo possibilita que o sujeito tenha consciência da realidade última escondida no símbolo da fé. $\mathrm{O}$ 
símbolo religioso tem a capacidade de abrir níveis da realidade que a linguagem não simbólica desconhece, ou seja, níveis da alma e da nossa realidade interior em relação com níveis da realidade exterior. "Assim, os símbolos têm dois lados. Abrem a realidade e, também, a alma", conclui Tillich (Idem, p.101).

$\mathrm{O}$ que justificaria o interesse da sociedade plural no discurso sobre Deus e suas correspondentes crenças no espaço público? Para Tillich, o que dá sentido à cultura é a religião. Ele afirma que:

A religião, considerada preocupação suprema, é a substância que dá sentido à cultura, e a cultura, por sua vez, é a totalidade das formas que expressam as preocupações básicas da religião. Em resumo: religião é a substância da cultura e a cultura é a forma da religião. Com isso evita-se o dualismo entre religião e cultura. Cada ato religioso, não apenas da religião organizada, mas também dos mais íntimos movimentos da alma, é formado culturalmente (Idem, p.83).

Ora se as convicções religiosas têm incidências culturais e sociais, é necessário expor publicamente suas razões e fundamentos. É um ganho para a democracia o diálogo entre razões e convicções de fé e a cidadania. O teólogo que daí participa se coloca em condições de mostrar à sociedade a importância das religiões na construção de um mundo melhor. Segundo Márcio Fabri dos Anjos:

A sociedade plural ganha com o diálogo entre as confessionalidades e religiões. É reconhecido o potencial das religiões e confessionalidades para cultivar valores e convicções. Os laços comunitários de pertença facilitam e dinamizam as representações e práticas relacionadas com a fé [...] Hans Küng desenvolveu um projeto de "ethos" mundial em vista da sobrevivência humana, visando diretamente as religiões do mundo. Argumenta que, no ingente desafio político e econômico da paz mundial, a contribuição das religiões é indispensável [...] É conveniente que as religiões e confessionalidades possam discutir entre si as suas razões teológicas em vista de temas e desafios da convivência social. Não só pelo estrago social dos conflitos religiosos que o diálogo pode evitar, mas também pela soma de esforços construtivos que ele pode proporcionar (ANJOS, 2011, p.127-129).

O princípio da correlação afirma a necessidade de pensar qualquer realidade juntamente com outra realidade, na medida em que elas se 
encontram em relação de dependência recíproca. A tarefa do teólogo consiste em participar ativamente da realidade analisando primeiramente a situação humana, utilizando todas as fontes culturais disponíveis na busca de identificar as perguntas existenciais para, num segundo momento, demonstrar que os símbolos cristãos constituem a resposta a tais questões.

Para Tillich, Deus, o Incondicionado, não está preso a uma determinada cultura, mas ele é o fundamento de todas as expressões culturais existentes, isto é, ele está atuando mesmo dentro de uma cultura secular. Assim a combinação entre a tradição cristã e o ambiente secular, com a crença da presença do Logos no espírito de todas as pessoas e, sobretudo presente em todas as culturas, desembocou em seu entendimento da interdependência recíproca entre cultura e religião.

Uns dos benefícios da correlação entre a situação e a mensagem para a teologia pública é que esta polaridade, como evento epistemológico, abriu aos teólogos novos vocabulários, estabelecendo o diálogo entre os contextos religiosos e os contextos culturais em seus mais diversos matizes. O vocabulário teológico está entre os novos vocabulários possíveis. Por exemplo, no último capítulo da Teologia da Cultura, Tillich dá orientações sobre a comunicação efetiva da mensagem cristã, ressignificando categorias cristãs que ele julga serem ultrapassadas e carregadas de equívocos, e que dificultariam o seu entendimento na contemporaneidade. Não se trata de simples mudança de nome. É mais do que isto. É um esforço em busca de potencializar a força do símbolo religioso, manifestando a relevância de sua mensagem para o sujeito contemporâneo.

\section{Considerações finais}

Os estudiosos da religião sugerem que a crise religiosa de hoje apresenta as seguintes características: primeira, a crise não é terminal para o religioso, e sim de mudança estrutural; segunda, as religiões históricas tradicionais perderam a sua força por não conseguirem ter o que dizer a atual geração; e, terceira, observa-se uma emergência de novas formas religiosas criativas potencializando a espiritualidade humana. Importante ressaltar que a crise religiosa atual está desassociada com a espiritualidade. Segundo José Maria Vigil: 
A espiritualidade não é, como se pensou tradicionalmente, um subproduto da religião, uma atitude produzida pela religião em seus adeptos; pelo contrário, a religião é que é simplesmente uma forma dentre muitas nas quais se pode expressar essa realidade abrangente e maximamente profunda que é a espiritualidade, acessível a todo ser humano, antes e na base de sua adesão a uma religião. [...] O que está em crise hoje não é o espiritual - que, pelo contrário, mostra exuberante vitalidade, reclamando espaços e novas formas de expressão onde as velhas entraram em crise - e sim algumas formas do religioso, especialmente as religiões institucionais tradicionais (VIGIL, 2006, p.350).

O pensamento fronteiriço de Tillich, como um espaço entre lugares e para além das religiões, sem desconsiderá-las, é claro, pode ser um caminho interessante para uma teologia com uma consciência planetária nesta nova sociedade do conhecimento. O serviço ao mundo, ao planeta e à humanidade são considerados como critérios mais importantes do que a pertença religiosa para a qualidade da teologia. Não que o enraizamento em uma tradição de fé não seja importante, mas ela não é determinante para o fazer teológico. Emerge na contemporaneidade uma sabedoria teológica no mundo irreligioso, preocupada com a situação do mundo e para além das fronteiras das religiões. Nesse contexto, o nosso teólogo da fronteira tem muito o que dizer.

\section{Referências}

AGOSTINI, Nilo. Ética cristã e desafios atuais. Rio de Janeiro: Vozes, 2002. ANJOS, Márcio Fabri dos. Teologia como profissão: da confessionalidade à esfera pública. In: SOARES, Afonso Maria; PASSOS, João Décio. (Orgs.). Teologia pública: reflexões sobre uma área de conhecimento e sua cidadania acadêmica. São Paulo: Paulinas, 2011.

BOTTON, Alain. Religião para ateus. Rio de Janeiro: Intrínseca, 2011.

CORBÍ, Marià. Para uma espiritualidade leiga: sem crenças, sem religiões, sem deuses. São Paulo: Paulus, 2010.

CUNHA, Carlos. Provocações decoloniais à teologia cristã. São Paulo: Ed. Terceira Via, 2017.

; LIBANIO, J.B. Linguagens sobre Jesus: as linguagens tradicional, neotradicional pós-moderna, carismática, espírita e neopentecostal. São Paulo: Paulus, 2011. 
FREIRE, Paulo. Ação cultural para a liberdade. 5.ed. Rio de Janeiro: Paz e Terra, 1981.

GIRARD, René. Eu via Satanás cair como um relâmpago. São Paulo: Paz e Terra, 2012.

LAPLANTINE, François. Aprender antropologia. São Paulo: Brasiliense, 2003.

LIBANIO, J.B.; MURAD, Afonso. Introdução à teologia: perfil, enfoques e tarefas. 3.ed. São Paulo: Loyola, 2001.

LIBANIO, João Batista. A religião no início do milênio. São Paulo: Loyola, 2002a.

As lógicas da cidade: o impacto sobre a fé e sob o impacto da fé. 2.ed. São Paulo: Loyola, 2002b.

ONU-Habitat lança ferramenta que mede ritmo da urbanização global. Disponível em: <https://nacoesunidas.org/onu-habitat-lanca-ferramenta-mede-ritmo-urbanizacao-global/>. Acesso em 1 de nov. 2019.

PINHEIRO, Jorge. Tillich, teólogo da cultura. In: TILLICH, Paul. Teologia da cultura. São Paulo: Fonte Editorial, 2009.

RIBEIRO, Pedro. A desafeição religiosa de jovens e adolescentes. Disponível em: <http://www.ihu.unisinos.br/entrevistas/511180-desafeicao-religiosa-esse-conceito-seria-central-para-entendermos-os-sem-religiao-entrevista-especial-com-pedro-ribeiro-de-oliveira>. Acesso em 1 nov. 2019.

SOBRINO, Jon. A fé em Jesus Cristo: ensaio a partir das vítimas. Petrópolis: Vozes, 2000.

TILLICH, Paul. A coragem de ser. Rio de Janeiro: Paz e Terra, 1972.

. Teologia da cultura. São Paulo: Fonte Editorial, 2009.

. Teologia sistemática. 5.ed. rev. São Leopoldo: Sinodal, 2005.

Sons, 1948.

. The Shaking of the Foundations. New York: Charles Scribner's

VIGIL, José Maria. A crise da vida religiosa na Europa do século XXI: tema de reflexão para a vida religiosa latino-americana. Ciberteologia - Revista de Teologia \& Cultura, Ano VI, n. 31, p. 29-14.

Teologia do pluralismo religioso: para uma releitura pluralista do cristianismo. São Paulo: Paulus, 2006. 